\title{
New Insights in Adherence and Survival in Myotonic Dystrophy Patients Using Home Mechanical Ventilation
}

\author{
Charlotte Seijger $^{\mathrm{a}} \quad$ Joost Raaphorst $^{\mathrm{b}} \quad$ Judith Vonk $^{\mathrm{c}}$ Baziel van Engelen ${ }^{\mathrm{d}}$ \\ Harry Heijerman ${ }^{\mathrm{e}}$ Nadine Stigter $^{\mathrm{e}}$ Peter Wijkstra $^{\mathrm{a}}$ \\ aDepartment of Pulmonary Diseases and Home Mechanical Ventilation, University of Groningen, University Medical \\ Centre Groningen, Groningen, The Netherlands; b Department of Neurology, Amsterdam Neuroscience, University \\ of Amsterdam, Amsterdam UMC, Amsterdam, The Netherlands; 'Department of Epidemiology, University \\ of Groningen, University Medical Centre Groningen, Groningen, The Netherlands; 'Department of Neurology, \\ Donders Institute for Brain, Cognition and Behaviour, Radboud University Medical Centre, \\ Nijmegen, The Netherlands; ' Department of Pulmonary Diseases, Utrecht University, University Medical Centre \\ Utrecht, Utrecht, The Netherlands
}

\section{Keywords}

Myotonic dystrophy $\cdot$ Respiratory failure $\cdot$ Home mechanical ventilation · Adherence · Survival

\begin{abstract}
Background: Non-invasive home mechanical ventilation (HMV) is a complex treatment in myotonic dystrophy type 1 (DM1) patients, due to a presumed poor adherence, variable symptom improvement, and uncertainty regarding survival benefits. Objectives: We aimed to investigate indications, adherence to HMV and its effects on mortality in a large cohort of DM1 patients. Methods: In this retrospective cohort study, we evaluated 224 DM1 patients. Different groups based on hypercapnia and HMV treatment were compared. Cox regression analyses were performed to compare mortality between different defined groups. Results: 224 patients were analysed of whom 111 started non-invasive HMV. Indications were daytime hypercapnia $(n=75)$, only nocturnal hypercapnia $(n=33)$, or other reasons $(n=3)$. Adequate adherence ( $\geq 4 \mathrm{~h} / \mathrm{night}$ ) was found in $84.9 \%$ of patients. Adequate ventilation was reached in $86.5 \%$ of patients. In 33 patients $(29.7 \%), \mathrm{HMV}$ was stopped prematurely due to not reaching patients' expectations on symptom relief or treat-
\end{abstract}

karger@karger.com www.karger.com/res

Karger"

BOPEN ACCESS
(C) 2021 The Author(s)

Published by S. Karger AG, Basel

This is an Open Access article licensed under the Creative Commons Attribution-NonCommercial-4.0 International License (CC BY-NC) (http://www.karger.com/Services/OpenAccessLicense), applicable to the online version of the article only. Usage and distribution for commercial purposes requires written permission. ment burden $(n=22)$, or intolerance $(n=8)$, or other reasons $(n=3)$. HMV did not improve survival in daytime hypercapnic patients $(p=0.61)$ nor in nocturnal hypercapnia patients compared to daytime hypercapnia $(p=0.21)$. Significant survival benefits after starting HMV were found for patients with HMV adherence $\geq 5 \mathrm{~h} / 24 \mathrm{~h}$ compared to patients who used HMV less. Conclusion: In this large cohort, daytime hypercapnia is the main reason for starting HMV, which is well tolerated and used. Mortality is not associated with the reason why HMV was started, but once started, patients with $\geq 5$ $\mathrm{h} / 24 \mathrm{~h}$ adherence have significantly better survival compared to patients who use it less. @ 2021 The Author(s)

Published by S. Karger AG, Basel

\section{Introduction}

Myotonic dystrophy type 1 (DM1) is the most frequent inherited adult-onset muscular dystrophy, with an estimated prevalence of 1 in 8,000 individuals [1]. Life expectancy is markedly reduced with a mean age at death of 54 years [2]. In nearly half of the patients, mortality is due to respiratory failure caused by respiratory muscle weakness leading to hypercapnia [2]. Other important 
factors related to respiratory dysfunction in DM1 are intercurrent atelectasis or pneumonia, sleep apnoea, and decreased lung volumes due to respiratory muscle weakness and overweight [2-4].

Long-term non-invasive ventilation, using bilevel positive airway pressure, further called home mechanical ventilation (HMV), may relieve respiratory failure symptoms, normalization of gas exchange, and may improve life expectancy in DM1 patients $[5,6]$. However, HMV is a complex treatment in DM1 patients. It is unpredictable if a DM1 patient experiences benefits of HMV, as the common complaint of excessive sleep at daytime could also be caused by central nervous system dysfunction or otherwise be related to fatigue which is common in DM1 [7-9]. Also, adherence to HMV is presumed to be poor due to cognitive and behavioural impairment (e.g., apathy) in DM1 patients $[10,11]$. Despite the existence of recommendations and guidelines when to start HMV, it remains a challenge to find the optimal timing of initiating HMV in an individual DM1 patient $[12,13]$. Finally, the effect of HMV on mortality has not been established in multiple and large studies $[5,6]$.

We hypothesize that survival will be related to the severity of alveolar hypoventilation (better survival in nocturnal hypercapnia than daytime hypercapnia) and adherence to HMV. In this observational study we investigated in a large cohort DM1 patients the indications and adherence for non-invasive HMV. Secondly, whether mortality is associated with the HMV indication and if we could determine how many hours HMV should be minimally used to result in survival benefits.

\section{Methods}

\section{Patient Selection and Study Design}

All DM1 patients referred to the HMV centre of the University Medical Centre Utrecht (UMCU) between 1996 and 2018 were identified, and their electronic medical records were evaluated for this retrospective observational study. Exclusion criteria were as follows: the use of invasive mechanical ventilation, other neurological comorbidities which could contribute to the development of respiratory failure, or when HMV was already started electively in another HMV centre.

The diagnosis of DM1 was made by a neurologist before referral. In the Netherlands, patients with DM1 are diagnosed in tertiary referral centres for neuromuscular disorders. The diagnosis is based on clinical examination and since 1992 on genetic confirmation, mostly in the patient or at least in a first degree family member, of the repeat length polymorphism in the DMPK gene [14].

Confirmed by the Ethics Committee from the UMCU, this retrospective study with anonymized data did not need approval as this study did not fall within the remit of the Medical Research
Involving Human Subject Act (WMO) [15]. Performed investigations were done primarily for clinical use and patients automatically agree with the use of their data (anonymized) for research. Patients need to disagree actively if they do not wish that their data will be used for research. This study was also conducted in accordance with the amended Declaration of Helsinki.

\section{Assessment at HMV Centre}

Indications for referral to the HMV centre were the presence (or expected in the near future) of respiratory failure type 2 defined as daytime hypercapnia $\left(\mathrm{pCO}_{2} \geq 45.0 \mathrm{~mm} \mathrm{Hg}\right.$ ), or if vital capacity drops below $50 \%$ of predicted, or when symptoms of respiratory failure or nocturnal hypoventilation/hypercapnia (night-time $\mathrm{pCO}_{2} \geq 45.0 \mathrm{~mm} \mathrm{Hg}$ ) are present, like excessive daytime sleepiness, morning headache, dyspnoea, and disturbed sleep [13].

The assessment by the HMV physician includes daytime capillary blood gas analysis, pulmonary function, and BMI. Often, forced vital capacity (FVC), forced expiratory volume in $1 \mathrm{~s}$, and maximal inspiratory and expiratory mouth pressures are measured (PI- and PEmax). If nocturnal hypoventilation is suspected, further assessment with blood gas analyses (arterial or capillary), or transcutaneous $\mathrm{CO}_{2}\left(\mathrm{TcCO}_{2}\right)$ level monitoring (by SenTec or TOSCA) during night-time is performed.

\section{Starting HMV}

Considerations about starting HMV in DM1 patients are made individually. Presence of daytime or only nocturnal hypercapnia together with symptoms related to respiratory failure are the main reasons to start HMV. Daytime hypercapnia is defined as hypercapnia $\left(\mathrm{pCO}_{2} \geq 45.0 \mathrm{~mm} \mathrm{Hg}\right.$ ) measured during daytime which in general is also present at night-time. Nocturnal hypercapnia is only present at night-time and normalizes during the morning, which means that daytime blood gas analyses show normocapnia. Non-invasive ventilation, using bilevel positive airway pressure, is started in the hospital during a 4-5-day admission. The settings are individualized to every patient by titrating on nocturnal transcutaneous $\mathrm{CO}_{2}$ with additional blood gas analyses, aiming to normalize gas exchange. A team of HMV skilled nurses (mainly former ICU nurses) supervise patients both during the set-up in the hospital and also visit them at home afterwards annually. They give education based on a learning management system, which includes both e-learning modules, as well as hands on education.

When patients are in a stable condition, follow-up visits are every 6-12 months at the outpatient clinic and in case of HMV also at home by a specialized nurse. Gas exchange is checked annually by nocturnal $\mathrm{TcCO}_{2}$ and daytime $\mathrm{pCO}_{2}$ measurements. Adherence to HMV is investigated by checking the memory card of the patient's device for the mean time in hours that a patient used the device per night. Optimal adherence time to HMV in DM1 patients is not known yet. In sleep studies a cut-off point of at least 5 $\mathrm{h}$ is defined as good adherence [16]. In this study we use a cut-off point of at least $5 \mathrm{~h}$ use per night as a good adherence, compared to other DM1 studies $[5,6]$.

\section{Statistical Analyses}

Data analysis was performed using IBM-SPSS-Statistics, version 23.0. Patients were stratified in subgroups based on results of blood gas analyses and starting HMV. Variables were checked for a normal distribution using P-P plots and histograms. In case of a 


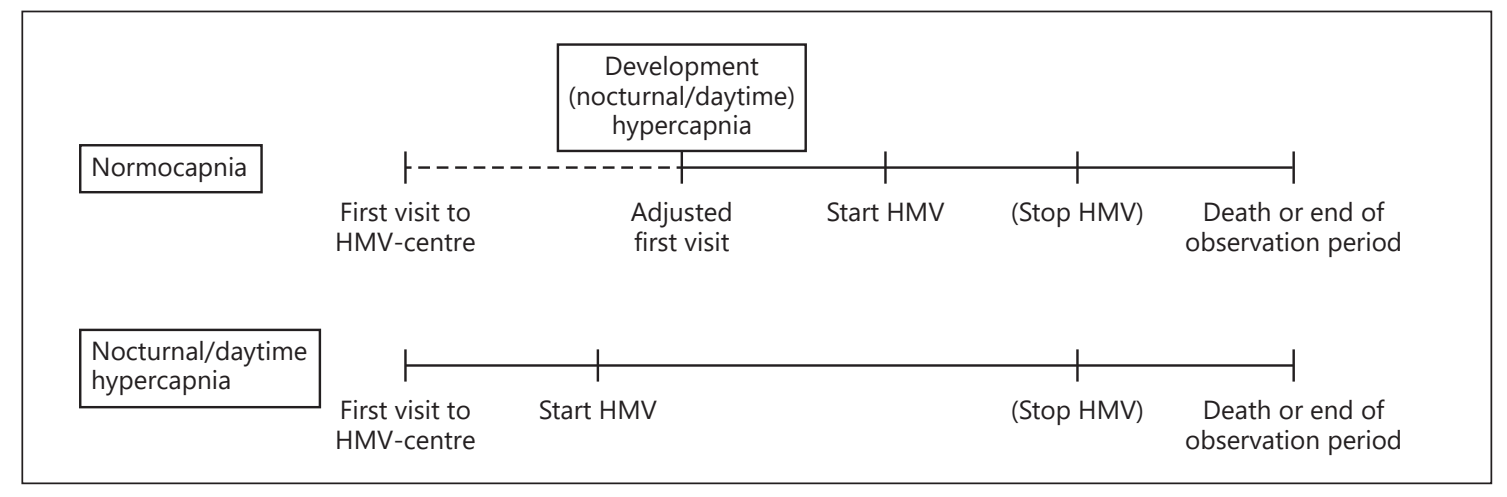

Fig. 1. Overview of survival time. HMV, home mechanical ventilation.

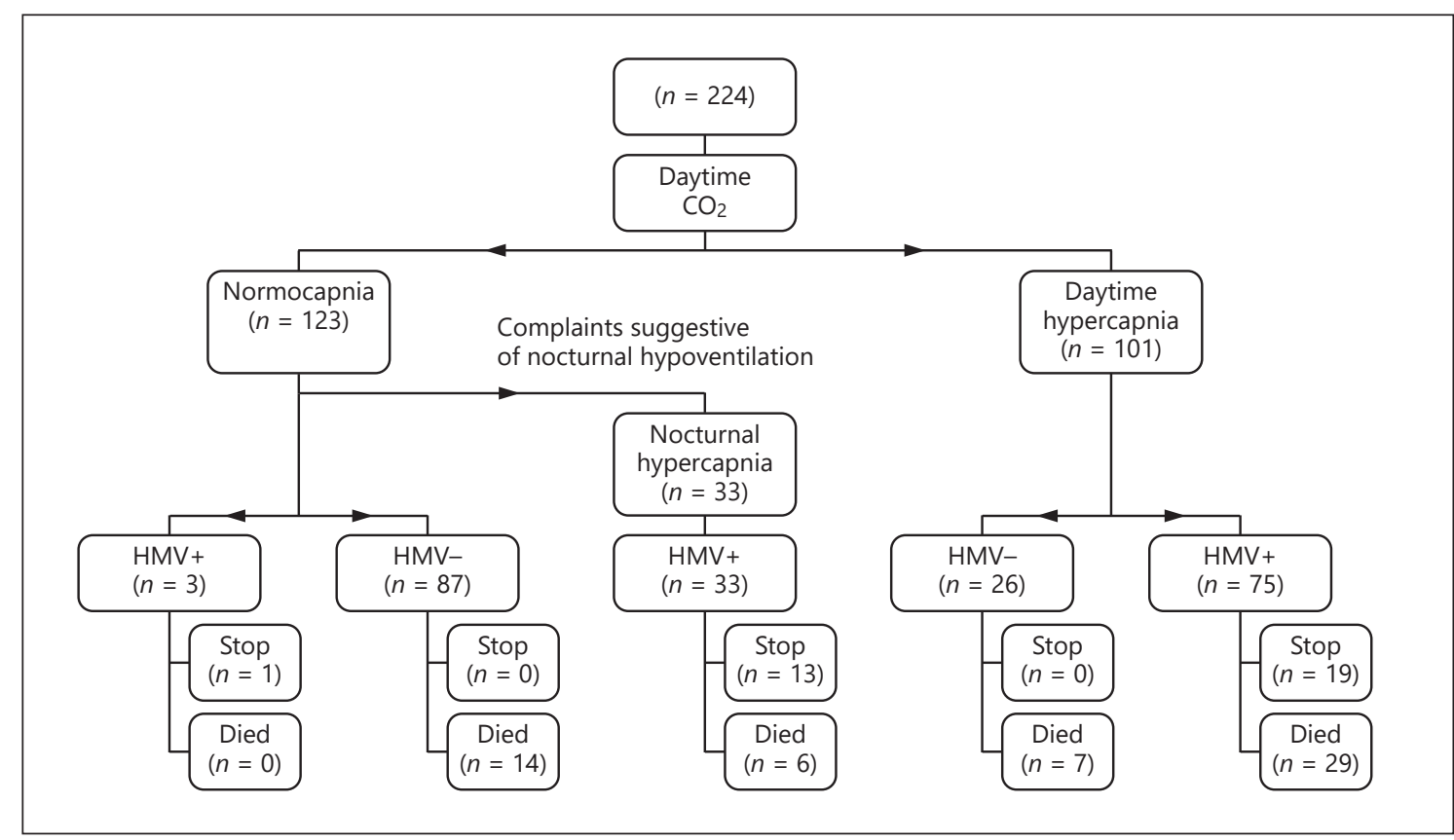

Fig. 2. Flow diagram of $224 \mathrm{DM} 1$ patients stratified for $\mathrm{pCO}_{2}$ and the initiation of HMV. DM1, myotonic dystrophy type 1; HMV, home mechanical ventilation.

normal distribution, the mean \pm standard deviation is presented, otherwise the median and range. Results of pulmonary function tests are expressed in percentage of individuals' predicted values (\%pred.), using reference values of Quanjer et al. [17]. Paired $t$ testing is used to compare the results of the pulmonary function test to the individuals' predicted values and to analyse changes in gas exchange before and after at least 3 months of HMV. ANOVA testing is used to analyse differences in pulmonary function tests between groups. The $\chi^{2}$ statistic is used for testing relationships between categorical variables. Survival time was calculated in months between the first visit and end of observation period (September 2018) or date of death. To calculate survival time, the date of first visit was adjusted to the moment (nocturnal) hypercapnia was as- sessed in case of normocapnia at daytime during the first visit (Fig. 1). Living status was verified for all patients in patients' electronic medical file.

To analyse differences in mortality between subgroups of patients, a Cox proportional hazard regression analysis is used and the event is defined as death (due to any cause). The model is corrected for gender and baseline significant contributors to survival, calculated by univariate Cox regression analyses ( $p$ value $<0.15$ ).

To analyse the influence of HMV adherence to mortality, additional analyses with different definitions for adherence time to HMV were performed. Kaplan-Meier curves are presented for survival analyses. $p$ value $<0.05$ is considered statistically significant in all statistical tests. 
Table 1. Baseline characteristics and pulmonary function

\begin{tabular}{|c|c|c|c|c|c|c|c|c|c|c|c|}
\hline & $\begin{array}{l}\text { DM1, } \\
n=224\end{array}$ & $N^{\mathrm{a}}$ & $\begin{array}{l}\text { Normocapnia, } \\
n=90\end{array}$ & $N^{a}$ & $\begin{array}{l}\text { Nocturnal } \\
\text { hypercapnia and } \\
\text { HMV, } n=33\end{array}$ & $N^{a}$ & $\begin{array}{l}\text { Daytime } \\
\text { hypercapnia and } \\
\text { HMV, } n=75\end{array}$ & $N^{\mathrm{a}}$ & $\begin{array}{l}\text { Daytime } \\
\text { hypercapnia } \\
\text { without HMV, } \\
n=26\end{array}$ & $N^{a}$ & $\begin{array}{l}p \\
\text { value }^{\mathrm{b}}\end{array}$ \\
\hline Age, years & $43 \pm 13$ & 224 & $42 \pm 13$ & & $44 \pm 11$ & & $44 \pm 14$ & & $45 \pm 13$ & & 0.48 \\
\hline Male, $n(\%)$ & $119(53.1)$ & 224 & $41(45.6)$ & & $20(60.6)$ & & $39(52.0)$ & & $19(73.1)$ & & 0.07 \\
\hline Smoking yes/no & $25 / 150$ & 175 & $9 / 56$ & 65 & $1 / 29$ & 30 & $12 / 48$ & 60 & $3 / 17$ & 20 & 0.20 \\
\hline \multicolumn{12}{|c|}{ Pulmonary function } \\
\hline FVC, \%pred. & $68.5 \pm 20.3^{\#}$ & 167 & $71.1 \pm 18.5$ & 76 & $74.2 \pm 18.4$ & 25 & $63.1 \pm 24.8$ & 42 & $64.1 \pm 16.7$ & 24 & 0.06 \\
\hline FEV1, \%pred. & $67.1 \pm 19.8^{\#}$ & 171 & $71.6 \pm 18.4$ & 75 & $70.6 \pm 16.5$ & 25 & $60.3 \pm 23.3$ & 46 & $62.4 \pm 15.7$ & 25 & 0.008 \\
\hline FEV1/FVC & $83.9 \pm 8.9$ & 167 & $85.0 \pm 10$ & 75 & $80.5 \pm 6.7$ & 25 & $84.7 \pm 7.7$ & 42 & $82.6 \pm 8.3$ & 24 & 0.12 \\
\hline PEF, \%pred. & $66.9 \pm 20.5^{\#}$ & 142 & $67.7 \pm 20.6$ & 68 & $73.6 \pm 19.3$ & 18 & $60.9 \pm 23.2$ & 35 & $68.5 \pm 14.1$ & 21 & 0.17 \\
\hline PImax, \%pred. & $58.6 \pm 22.8^{\#}$ & 131 & $57.7 \pm 19.5$ & 65 & $66.3 \pm 26.0$ & 19 & $58.5 \pm 27.8$ & 29 & $53.8 \pm 21.2$ & 18 & 0.39 \\
\hline
\end{tabular}

Data are presented as mean with standard deviation or $n(\%)$. DM1, myotonic dystrophy type 1; HMV, home mechanical ventilation; FVC, forced vital

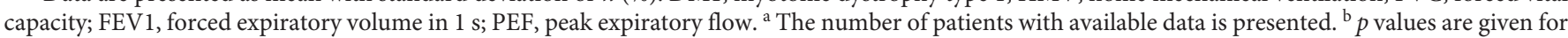
ANOVA tests (continuous data) or $\chi^{2}$ tests (discrete data) between the 4 different subgroups. ${ }^{*} p<0.001$ for a paired $t$ test between measured and predicted values.

\section{Results}

\section{First Visit to HMV Centre}

241 DM1 patients visited the HMV centre between 1996 and 2018, of whom 17 patients are excluded because patients used invasive mechanical ventilation $(n=10)$, HMV was already started in another HMV centre $(n=5)$ or due to comorbidity (Guillain-Barré and spinal cord injury [ $n=2]$ ). A total of $224 \mathrm{DM} 1$ patients were analysed. Figure 2 shows stratified groups based on blood gas analyses and initiating HMV, including the outcomes "stop HMV" and "death." Four main groups are identified: (1) normocapnia at daytime without $\operatorname{HMV}(n=87)$; (2) nocturnal hypercapnia with HMV $(n=33)$; (3) hypercapnia at daytime with HMV $(n=75)$; and (4) hypercapnia at daytime without HMV $(n=26)$. Results of baseline characteristics and pulmonary function tests are presented in Table 1 for all patients and subgroups. Between groups, only forced expiratory volume in $1 \mathrm{~s}$ was significantly lower in patients with daytime hypercapnia compared to patients with normocapnia $(p=0.004)$.

\section{Home Mechanical Ventilation}

Figure 2 shows that the main reason for starting HMV is hypercapnia at daytime in 75 patients, represented by a median $\mathrm{pCO}_{2}$ of $49.0 \mathrm{~mm} \mathrm{Hg}$ in daytime blood gas (range 45.0-71.4 mm Hg). The median time between first visit and starting mechanical ventilation for all patients who started HMV was 61 days (minimum -76 days to a maximum of 4,157 days). In 4 of these patients mechanical ventilation was started in an acute setting before they visited the HMV centre, due to pneumonia, or temporarily after surgery or a rapid deterioration of respiratory failure, which explains the negative time value. HMV was started $\geq 1$ year after first visit in 24 patients (of whom 10 had nocturnal hypercapnia and 14 patients had daytime hypercapnia before the start of HMV), of which 1 patient started $>10$ years later.

\section{Hypercapnia at Daytime}

In the hypercapnia at daytime group, 19 (25.3\%) patients stopped HMV because it did not meet patients' expectations on symptom relief $(n=14)$, intolerance $(n=$ $3)$, air leaking with alarms $(n=1)$, or recovery of hypercapnia after cholecystectomy $(n=1)$. In 26 patients with daytime hypercapnia, HMV was not started due to the absence of complaints $(n=15)$, refusal by patients $(n=5)$, spontaneous recovery of hypercapnia, or due to symptom relief following adjustment of continuous positive airway pressure therapy $(n=4)$; 1 patient died before HMV could be started and 1 other patient was planned to start HMV at moment of study analyses.

\section{Nocturnal Hypercapnia}

The second reason of starting HMV is the presence of only nocturnal hypercapnia in 33 patients. In this sub- 
Table 2. Ventilatory settings and adherence in 111 patients using HMV

\begin{tabular}{|c|c|c|c|}
\hline & $\begin{array}{l}\text { All HMV } \\
\text { patients, } \\
n=111\end{array}$ & $\begin{array}{l}\text { Nocturnal } \\
\text { hypercapnia, } \\
n=33\end{array}$ & $\begin{array}{l}\text { Daytime } \\
\text { hypercapnia, } \\
n=75\end{array}$ \\
\hline Non-invasive, $\mathrm{n}$ & 111 & 33 & 75 \\
\hline Pressure/volume control, $n$ & $107 / 2$ & $32 / 0$ & $72 / 2$ \\
\hline \multicolumn{4}{|l|}{ Mask type } \\
\hline Full face, $n$ & 90 & 27 & 60 \\
\hline Nose, $n$ & 15 & 4 & 11 \\
\hline Nose pillows, $n$ & 2 & & 2 \\
\hline Hybrid, $n$ & 2 & 1 & 1 \\
\hline \multicolumn{4}{|l|}{ Ventilatory settings ${ }^{\mathrm{b}}$} \\
\hline IPAP, 103 & $16.6(3.4)$ & $16.1(3.2)$ & $16.9(3.6)$ \\
\hline EPAP, 101 & $5.9(2.3)$ & $6.2(2.4)$ & $5.7(2.3)$ \\
\hline Inspiratory time, $s$ & $1.4(0.3)$ & $1.4(0.3)$ & $1.3(0.3)$ \\
\hline Total $h$ per day, $n=106$ & $7.6(3.7)$ & $7.1(3.7)$ & $8.0(3.7)$ \\
\hline$<4 \mathrm{~h}, n(\%)$ & $16(15.1)$ & $6(18.2)$ & $9(12.0)$ \\
\hline $4 \leq \mathrm{h}<8, n(\%)$ & $21(19.8)$ & $5(15.2)$ & $14(18.7)$ \\
\hline $8 \leq \mathrm{h}<20, n(\%)$ & $68(64.2)$ & $19(57.6)$ & $49(65.3)$ \\
\hline $20 \leq \mathrm{h} \leq 24, n(\%)$ & $1(0.9)$ & & $1(1.3)$ \\
\hline \multicolumn{4}{|l|}{ Reasons to stop HMV } \\
\hline Did not reach expectations, $n$ & 23 & 9 & 14 \\
\hline Not tolerated, $n$ & 8 & 4 & 3 \\
\hline Other reasons, $n$ & 3 & & 2 \\
\hline
\end{tabular}

Table 3. Effects of mechanical ventilation on daytime and nocturnal gas exchange

\begin{tabular}{|c|c|c|c|c|c|}
\hline & Before HMV & Patients $^{\mathrm{a}}$ & $\begin{array}{l}\geq 3 \text { months after } \\
\text { starting HMV }\end{array}$ & Patients $^{\mathrm{a}}$ & $\begin{array}{l}\text { Paired } \\
T \text { test }\end{array}$ \\
\hline \multicolumn{6}{|c|}{ Daytime hypercapnia and $H M V: N=75$} \\
\hline Daytime $\mathrm{pCO}_{2}$ & $50.2(5.1)$ & 74 & $42.1(5.1)$ & 63 & $p<0.001$ \\
\hline Daytime $\mathrm{HCO}_{3}^{-}$ & $28.4(3.1)$ & 73 & $26.2(2.7)$ & 62 & $p<0.001$ \\
\hline Nocturnal mean $\mathrm{pCO}_{2}$ & na & 75 & $37.4(7.8)$ & 60 & na \\
\hline Nocturnal mean $\mathrm{SO}_{2}$ & na & 75 & $95.0(2.6)$ & 60 & na \\
\hline \multicolumn{6}{|c|}{ Nocturnal hypercapnia and $H M V: N=33$} \\
\hline Daytime $\mathrm{pCO}_{2}$ & $41.0(3.1)$ & 33 & $41.6(3.9)$ & 28 & $p=0.43$ \\
\hline Daytime $\mathrm{HCO}_{3}^{-}$ & $25.2(2.0)$ & 33 & $25.9(2.6)$ & 28 & $p=0.19$ \\
\hline Nocturnal mean $\mathrm{pCO}_{2}$ & $54.8(5.5$ & 30 & $38.4(5.3)$ & 27 & $p<0.001$ \\
\hline Nocturnal mean $\mathrm{SO}_{2}$ & $92.3(4.6)$ & 19 & $95.1(2.3)$ & 25 & $p=0.017$ \\
\hline
\end{tabular}

Values are expressed as mean with standard deviation. Daytime blood gas analyses are measured by arterial or capillary blood gas ( $\mathrm{mm} \mathrm{Hg}$ ). HMV, home mechanical ventilation; na, not available. ${ }^{\text {a }}$ Number of patients with data available for each measurement. 
Table 4. Univariate Cox regression model of contributors to mortality in all patients

\begin{tabular}{lllc}
\hline Variable & \multicolumn{2}{l}{ Univariate model } & \multirow{2}{*}{$p$ value } \\
\cline { 2 - 3 } & HR $(95 \% \mathrm{CI})$ & patients $^{\mathrm{a}}$ & \\
\hline Gender & $0.81(0.48-1.38)$ & 224 & 0.45 \\
BMI & $1.03(0.99-1.08)$ & 203 & 0.14 \\
Age at first visit & $1.07(1.05-1.1)$ & 224 & $<0.001$ \\
FVC, \% of pred. & $0.97(0.95-0.99)$ & 167 & $<0.001$ \\
$\mathrm{PaCO}_{2}$ daytime & $1.09(1.05-1.14)$ & 220 & $<0.001$ \\
\hline
\end{tabular}

FVC, forced vital capacity. ${ }^{a}$ Number of patients with data available for each measurement.

Table 5. Cox regression analyses for different definitions of HMV adherence

\begin{tabular}{|c|c|c|c|c|}
\hline \multirow[t]{2}{*}{ Adherence } & \multirow{2}{*}{$\begin{array}{l}\text { Patients } \\
\text { adherent/ } \\
\text { non-adherent }\end{array}$} & \multicolumn{3}{|c|}{ Reference group: non-adherence ${ }^{a}$} \\
\hline & & $\begin{array}{l}\text { mortality hazard } \\
\text { ratio }\end{array}$ & $\begin{array}{l}95 \% \text { confidence } \\
\text { interval }\end{array}$ & $\begin{array}{l}p \\
\text { value }\end{array}$ \\
\hline$\geq 3 \mathrm{~h} / 24 \mathrm{~h}$ & $93 / 13$ & 0.52 & $0.11-2.4$ & 0.40 \\
\hline$\geq 4 \mathrm{~h} / 24 \mathrm{~h}$ & $90 / 16$ & 0.33 & $0.09-1.27$ & 0.11 \\
\hline$\geq 5 \mathrm{~h} / 24 \mathrm{~h}$ & $83 / 23$ & 0.30 & $0.09-0.96$ & 0.04 \\
\hline$\geq 6 \mathrm{~h} / 24 \mathrm{~h}$ & $80 / 26$ & 0.24 & $0.08-0.74$ & 0.013 \\
\hline$\geq 7 \mathrm{~h} / 24 \mathrm{~h}$ & $78 / 28$ & 0.20 & $0.07-0.62$ & 0.005 \\
\hline$\geq 8 \mathrm{~h} / 24 \mathrm{~h}$ & $68 / 38$ & 0.42 & $0.16-1.14$ & 0.087 \\
\hline
\end{tabular}

HMV, home mechanical ventilation. ${ }^{\text {a }}$ Reference group is defined as less hours than defined adherence group.

group the median night-time $\mathrm{pCO}_{2}$ was 48.9 (range 48.0$65.0 \mathrm{~mm} \mathrm{Hg}$ ). HMV was stopped in 13 patients (39\%), due to not reaching patients' expectations on symptom relief $(n=9)$ or intolerance $(n=4)$. In a small group of 3 patients, HMV was started without the presence of hypercapnia due to complaints of disturbed sleep $(n=2)$ and central sleep apnoea $(n=1)$.

\section{Adherence and Efficacy of $H M V$}

Overall, 111 started on non-invasive HMV, mostly delivered by full face mask. In Table 2 the ventilatory settings and adherence are presented. Mean (SD) hours of HMV use is $7.6 \pm 3.7 \mathrm{~h}$ a day. In 90 (84.9\%) patients adequate adherence of $>4 \mathrm{~h}$ a day is reached. Between patients with nocturnal hypercapnia using HMV and daytime hypercapnia using HMV, no significant differences are found in percentages of patients with adequate adher- ence (resp. 80 vs. $87.7 \%$, Pearson $\chi^{2} 1.01, p=0.32$ ). In a total of 31 patients (27.9\%), HMV was stopped, mainly as treatment did not reach patients' expectations if symptom improvement or burdens of treatment did not outweigh benefits $(n=23)$ or HMV was not tolerated $(n=8)$.

Daytime and nocturnal gas exchange data before the start of HMV and after at least 3 months of HMV treatment are presented in Table 3. An adequate gas exchange, defined as a mean $\mathrm{pCO}_{2}<45.0 \mathrm{~mm} \mathrm{Hg}$ during night with $\mathrm{HMV}$, is reached in $52(86.7 \%)$ patients (available data of $n=60$ ) with daytime hypercapnia. In patients with only nocturnal hypercapnia, adequate gas exchange is reached in $24(88.9 \%)$ patients (available data of $n=27$ ).

\section{Cox Regression Analyses}

Total follow-up period for 224 patients was 1,227 patient-years. No loss to follow-up occurred for data about mortality. In total 56 patients $(25.0 \%)$ died at a mean age of $55.4 \pm 8.8$ years, with an annual rate of $56 / 1,227$ (4.6\%). Table 4 shows the results of univariate Cox regression analyses to identify baseline factors associated with mortality. Three baseline factors were significantly associated with mortality: age at first visit (HR 1.07 and $p<0.001$ ), FVC (HR 0.97 and $p<0.001$ ), and $\mathrm{PaCO}_{2}$ during daytime (HR 1.09 and $p<0.001$ ). BMI and peak expiratory flow were not significantly correlated to mortality.

A Cox proportional hazards model is performed to analyse significant contributors to mortality. In this model only age at first visit (HR 1.08 and $p=<0.001$ ) and FVC (HR 0.96 and $p<0.001$ ) are significant contributors to mortality.

\section{HMV Indication and Mortality}

Subgroup analyses were performed to analyse the effect of HMV indication on mortality, analyses were adjusted for gender, age at first visit, and FVC. Patients with daytime hypercapnia with and without HMV did not show significant differences in survival analyses (HR 1.52, $95 \%$ CI $0.30-7.66$, and $p=0.61$ ). Neither significant differences were found between patients with daytime hypercapnia using HMV compared to nocturnal hypercapnia using HMV patients (HR 3.22, 95\% CI 0.52-19.82, and $p=0.21)$. Results are visualized in Figure 3 a.

\section{HMV Adherence and Mortality}

To analyse the association between adherence and mortality, a new variable was included for HMV adherence (no use, adherent, and non-adherent) in a Cox proportional hazards model which is adjusted for gender, age at first visit, and FVC. An adherence of $\geq 4 \mathrm{~h} / 24 \mathrm{~h}$ was not 

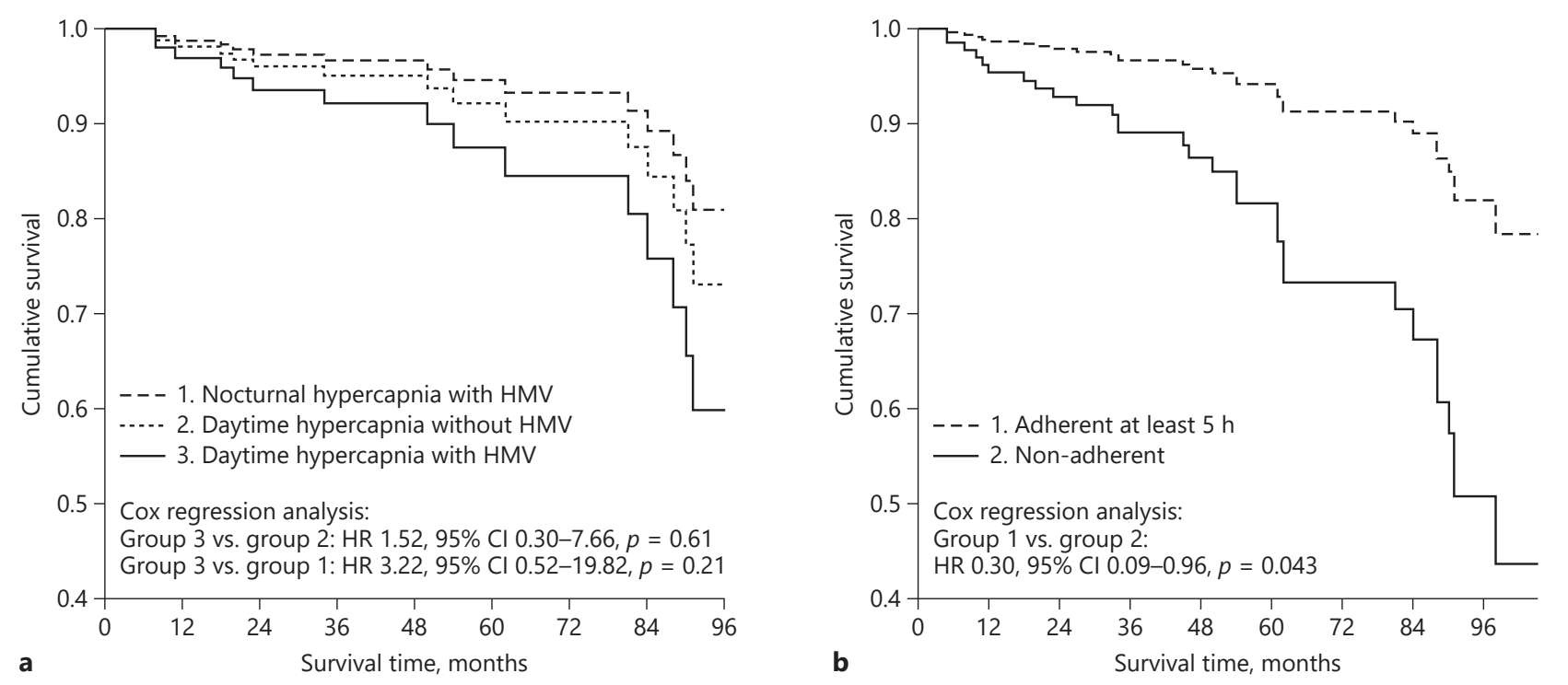

Fig. 3. a Kaplan-Meier curve showing HMV indication and its effect on mortality. b Kaplan-Meier curve showing HMV adherence and its effect on mortality. HMV, home mechanical ventilation.

significantly associated with less mortality compared to patients who use HMV $<4$ h/24 h (HR 0.33, 95\% CI 0.091.27 , and $p=0.11$ ). Additional analyses with different definitions for adherence time to HMV, showed significant association with less mortality for patients with an adherence of $\geq 5 \mathrm{~h} / 24 \mathrm{~h}$ compared to patients who use their HMV less (HR: 0.30, 95\% CI 0.09-0.96, $p=0.043$ ). In 83 patients, HMV was used for $>5 \mathrm{~h} / 24 \mathrm{~h}$, of which baseline daytime $\mathrm{pCO}_{2}$ of $47.7 \pm 6.5$ decreased to $42.0 \pm 4.8 \mathrm{~mm}$ $\mathrm{Hg}$ during $\mathrm{HMV}$, and mean nocturnal carbon dioxide values during HMV were $36.7 \pm 7.0$.

The highest survival benefits are found for patients who use their HMV $\geq 7 \mathrm{~h} / 24 \mathrm{~h}$ compared to patients who use their HMV $<7 \mathrm{~h} / 24 \mathrm{~h}$ (HR 0.20, 95\% CI 0.07-0.62, and $p=0.005)$. Results are shown in Table 5 and Figure $3 \mathrm{~b}$.

\section{Discussion}

In the present study, we investigated a large DM1 cohort from referral to an HMV centre until death or end of follow-up. Main indications for starting HMV were presence of daytime hypercapnia or only nocturnal hypercapnia with accompanying complaints. Adherence to HMV was remarkably high considering previous publications and results in normalizing gas exchange in most patients. Significant survival benefits are found when pa- tients use HMV for $\geq 5 \mathrm{~h} / 24 \mathrm{~h}$ compared to patients who use HMV less. Mortality is not associated to the reason for starting HMV (nocturnal hypercapnia or daytime hypercapnia); however, it is suggested that an earlier start (only nocturnal hypercapnia) also improved survival, compared to waiting for progressing to daytime hypercapnia.

As we found no statistical significant survival differences for HMV between nocturnal and daytime hypercapnic patients, it remains a challenge to determine the optimal time of starting HMV in DM1 patients. A possible reason for this finding could be that hypercapnia at daytime, which is the major indication for starting HMV, is a complex feature in DM1 patients. It is not always obvious whether complaints of excessive daytime sleepiness are related to hypercapnia due to alveolar hypoventilation or whether complaints originate from central nervous system dysfunction and associated hypersomnolence $[8$, 18]. Otherwise, hypercapnia is not always due to alveolar hypoventilation by respiratory pump failure but could also be related to a reduced ventilatory response to carbon dioxide in DM1 patients as well [19]. Therefore, it remains difficult in clinical practice to presume which hypercapnic DM1 patient will have benefits of HMV.

Adherence to HMV is remarkably high in this study. In $84.9 \%$ of patients HMV was used for $\geq 4$ h per night. This is much higher than in the cohort of Spiesshoefer 
and a bit higher than in the cohort of Boussaïd et al. [6] (76\%) [20]. These differences could be related to differences in baseline characteristics, as the patients in our cohort more often had daytime hypercapnia and therefore may have experienced more benefits from HMV than patients without respiratory failure. Also continuation of HMV, which occurred in $70.3 \%$ of our patients, is much higher as compared to the study of West et al. [18], which found a prevalence of $33 \%$ continuing HMV. Due to lacking information about settings, interfaces, and effects of HMV on gas exchange in the study of West et al. [18], it is not possible to explain this difference. In general, presence of respiratory failure symptoms and absence of excessive air leaking improves adherence to HMV [21]. In our study, only 1 patient ceased HMV due to excessive air leaking. This is probably related to the frequently used full face masks in our study cohort instead of nose masks which increases risk of air leakage by mouth during sleep, especially in DM1 patients with facial weakness. Unfortunately, we were not able to investigate effects of HMV on symptoms or quality of life. In future studies this should be assessed by using validated quality of life questionnaires in HMV users like the Severe Respiratory Insufficiency Questionnaire and the recently published $\mathrm{S}^{3}$-NIV questionnaire $[22,23]$.

An important outcome of the cox regression analysis is that an adherence $\geq 5 / \mathrm{h}$ to HMV significantly contributes to survival compared to patients who are less adherent. This finding confirms findings of Boussaïd et al. [6]. This suggest that extra education and motivation has to be given to patients and caregivers during outpatient clinic visits. Remarkably, mortality was not different for defined subgroups of indication of why HMV was started, which are shown in Figure 2. In this study, decisions about starting HMV were made on an individual basis, which could implicate that patients who started HMV had more advanced disease or worse prognosis compared to those patients who did not (want to) start.

Only 3 patients without hypercapnia started HMV in this study, which is very low compared to a recent study of Boussaid et al. [6]. This difference could be explained by the fact that in the Netherlands patients with obstructive or central sleep apnoea without clinical features of respiratory failure will be treated first with continuous positive airway pressure treatment without being referred to one of the 4 Dutch HMV centres.

This study has some limitations. Firstly, the retrospective design of the study implies missing data. For example, some blood gas and pulmonary function tests are lacking for different reasons, for example, patients who only visited the centre only for information about HMV or absence of recent performed tests or in some patients due to an acute start of HMV. This led to missing FVC results for $25.4 \%$ subjects in the survival analyses, and these subjects were therefore excluded from the analysis. An alternative is to use multiple imputation techniques to replace these missing data. We also performed the analyses after multiple imputation and this leads to the same conclusion (results not shown). Secondly, we were not able to correct for all known significant contributors to survival [24], as some of these results were not present in the medical files of the HMV centre. However, the 2 strongest predictors from a previously published prognostic model of a large French cohort study (age above 45 years and reduced vital capacity of $\leq 60 \%$ ) could be included [24]. We could not include the other known negative predictors which are cardiovascular risks and the need for support when walking. Thirdly, in a small group of 8 patients who were measured in the beginning of the study period, gas exchange during the night was measured by end-tidal $\mathrm{CO}_{2}$, which is less accurate in reflecting the real (arterial) $\mathrm{CO}_{2}$ compared to transcutaneous methods [25]. Therefore, we are not sure whether in these patients normalization of gas exchange is reached. Nowadays, only transcutaneous methods of $\mathrm{CO}_{2}$ measurements are performed during the night to monitor the ventilation. Finally, DM1 studies are difficult to compare because of the extreme variability of the disease, necessitating large cohort studies.

Our findings showed that HMV is tolerated well in hypercapnic patients and that HMV use of $\geq 5 \mathrm{~h} / 24 \mathrm{~h}$ significantly improves survival. But HMV remains a complex treatment in DM1 patients. This was already stated by O'Donoghue et al. [26] who showed that hypercapnic DM1 patients who electively discontinued HMV for 1 month did not decline in symptoms or quality of life. However, their study duration was very short and longterm effects of stopping or delaying initiation of HMV are not known. Thus, the low evidence base of HMV in DM1 patients, still offers opportunities for studies investigating effects of HMV on symptom relief, optimal adherence, and survival. The upcoming Dutch study "differential Response to non-invasive vEntilation in Myotonic DystrophY” (REMeDY study, registered as NL7972 in the Netherlands Trial Register), identifying which DM1 patient benefits of HMV, may provide useful data to guide decision-making on HMV in DM1. 


\section{Conclusion}

We found in this exceptional large cohort that daytime hypercapnia is the main reason for starting HMV, which is well tolerated and used. Survival is not influenced by the reason why HMV was started, but once started, patients with an adherence of $\geq 5 \mathrm{~h} / 24 \mathrm{~h}$ have significantly better survival compared to patients who are non-adherent. Probably, an early start of HMV (presence of only nocturnal hypercapnia) results in survival benefits compared to waiting for development of daytime hypercapnia. Due to the exceptional heterogeneity of DM1, further research is needed to identify which DM1 patients will benefit from HMV.

\section{Acknowledgement}

We thank Professor Y.F. Heijdra (pulmonologist at Radboud university medical centre, Nijmegen, the Netherlands) for her help with the study design.

\section{Statement of Ethics}

Confirmed by the Ethics Committee from the UMCU, this retrospective study with anonymized data did not need approval as this study did not fall within the remit of the Medical Research Involving Human Subject Act (WMO) [14]. Performed investigations were done primarily for clinical use and patients automatically agree with the use of their data (anonymized) for research.
Patients need to disagree actively if they do not wish that their data will be used for research. This study was also conducted in accordance with the amended Declaration of Helsinki.

\section{Conflict of Interest Statement}

C.S., J.R., J.V., H.H., and N.S. have no conflicts of interest to declare. BvE reports grants from FP7 European Union grant OPTIMISTIC, grants from Marigold Canada, all outside the submitted work. Dr. Wijkstra reports grants and personal fees from Philips; grants, personal fees, and others from RESMED; grants from VIVISOL, grants from Air Liquide, grants from Goedegebuure, personal fees from Bresotec, and personal fees from Synapse, all outside the submitted work.

\section{Funding Sources}

The authors received no specific funding for this work.

\section{Author Contributions}

C.G.W.S. had full access to all of the data in the study and takes responsibility for the integrity of the data and the accuracy of the data analysis. All authors contributed to study concept and design. C.G.W.S., J.M.V., and P.J.W. performed statistical analyses and all authors did interpretation of data. C.G.W.S. did the writing of the manuscript and was supervised by P.J.W. All authors contributed to critical review of the manuscript for important intellectual content. All authors approved the final version to be published and agreed to be accountable for all aspects of the work.

\section{References}

1 Harper PS. Myotonic dystrophy. 3rd ed London, UK: WB Saunders Co; 2001.

2 Groh WJ, Groh MR, Shen C, Monckton DG, Bodkin CL, Pascuzzi RM. Survival and CTG repeat expansion in adults with myotonic dystrophy type 1 . Muscle Nerve. 2011;43(5): $648-51$.

3 Seijger CG, Drost G, Posma JM, van Engelen BG, Heijdra YF. Overweight is an independent risk factor for reduced lung volumes in myotonic dystrophy type 1 . PLoS One. 2016; 11(3): 0152344.

4 Dauvilliers YA, Laberge L. Myotonic dystrophy type 1, daytime sleepiness and REM sleep dysregulation. Sleep Med Rev. 2012 Dec; 16(6):539-45.

5 Nugent AM, Smith IE, Shneerson JM. Domiciliary-assisted ventilation in patients with myotonic dystrophy. Chest. $2002 \mathrm{Feb} ; 121(2)$ : $459-64$.
6 Boussaïd G, Prigent H, Laforet P, Raphael JC, Annane D, Orlikowski D, et al. Effect and impact of mechanical ventilation in myotonic dystrophy type 1: a prospective cohort study. Thorax. 2018 Nov;73(11):1075-8.

7 Laberge L, Gagnon C, Dauvilliers Y. Daytime sleepiness and myotonic dystrophy. Curr Neurol Neurosci Rep. 2013 Apr;13(4):340-9.

8 Turner C, Hilton-Jones D. The myotonic dystrophies: diagnosis and management. J Neurol Neurosurg Psychiatry. 2010 Apr;81(4): 358-67.

9 Okkersen K, Jimenez-Moreno C, Wenninger S, Daidj F, Glennon J, Cumming S, et al. Cognitive behavioural therapy with optional graded exercise therapy in patients with severe fatigue with myotonic dystrophy type 1 : a multicentre, single-blind, randomised trial. Lancet Neurol. 2018;17(8):671-80.

10 Gallais B, Montreuil M, Gargiulo M, Eymard B, Gagnon C, Laberge L. Prevalence and correlates of apathy in myotonic dystrophy type 1. BMC Neurol. 2015;15:148.
11 Meola G, Sansone V. Cerebral involvement in myotonic dystrophies. Muscle Nerve. 2007; 36(3):294-306.

12 Boentert M, Cao M, Mass D, De Mattia E, Falcier E, Goncalves M, et al. Consensus-based care recommendations for pulmonologists treating adults with myotonic dystrophy type 1. Respiration. 2020;99:360-8.

13 Available from: https://www.vsca.nl/wp-content/uploads/Rapport_Veldnorm_Chronische_beademing_def.pdf.

14 Kamsteeg EJ, Kress W, Catalli C, Hertz JM, Witsch-Baumgartner M, Buckley MF, et al. Best practice guidelines and recommendations on the molecular diagnosis of myotonic dystrophy types 1 and 2. Eur J Hum Genet. 2012 Dec;20(12):1203-8.

15 Available from: https://www.umcutrecht.nl/ $\mathrm{nl} /$ Subsites/Medisch-Ethische-Toetsingscommissie/Is-toetsing-nodig. 
16 Labarca G, Reyes T, Jorquera J, Dreyse J, Drake L. CPAP in patients with obstructive sleep apnea and type 2 diabetes mellitus: systematic review and meta-analysis. Clin Respir J. 2018 Aug;12(8):2361-8.

17 Quanjer PH, Tammeling GJ, Cotes JE, Pedersen OF, Peslin R, Yernault JC. Lung volumes and forced ventilatory flows. Report working party standardization of lung function tests, European community for steel and coal. Official statement of the European respiratory society. Eur Respir J Suppl. 1993; 16;5-40.

18 West SD, Lochmüller H, Hughes J, Atalaia A, Marini-Bettolo C, Baudouin SV, et al. Sleepiness and sleep-related breathing disorders in myotonic dystrophy and responses to treatment: a prospective cohort study. J Neuromuscul Dis. 2016 Nov 29;3(4):529-37.

19 Poussel M, Thil C, Kaminsky P, Mercy M, Gomez E, Chaouat A, et al. Lack of correlation between the ventilatory response to $\mathrm{CO} 2$ and lung function impairment in myotonic dys- trophy patients: evidence for a dysregulation at central level. Neuromuscul Disord. 2015; 25(5):403-8.

20 Spiesshoefer J, Runte M, Heidbreder A, Dreher M, Young P, Brix T, et al. Sleep-disordered breathing and effects of non-invasive ventilation on objective sleep and nocturnal respiration in patients with myotonic dystrophy type I. Neuromuscul Disord. 2019;29(4): 302-9.

21 Boussaid G, Lofaso F, Santos DB, Vaugier I, Pottier S, Prigent H, et al. Factors influencing compliance with non-invasive ventilation at long-term in patients with myotonic dystrophy type 1: a prospective cohort. Neuromuscul Disord. 2016;26(10):666-74.

22 Windisch W, Freidel K, Schucher B, Baumann H, Wiebel M, Matthys H, et al. The severe respiratory insufficiency (SRI) questionnaire a specific measure of health-related quality of life in patients receiving home mechanical ventilation. J Clin Epidemiol. 2003; 56(8):752-9.
23 Dupuis-Lozeron E, Gex G, Pasquina P, Bridevaux PO, Borel JC, Soccal PM, et al. Development and validation of a simple tool for the assessment of home noninvasive ventilation: the S3-NIV questionnaire. Eur Respir J. 2018;52(5):1801182.

24 Wahbi K, Porcher R, Laforêt P, Fayssoil A, Bécane HM, Lazarus A, et al. Development and validation of a new scoring system to predict survival in patients with myotonic dystrophy type 1. JAMA Neurol. 2018;75(5):573-81.

25 Janssens JP, Borel JC, Pépin JL, Group S. Nocturnal monitoring of home non-invasive ventilation: the contribution of simple tools such as pulse oximetry, capnography, built-in ventilator software and autonomic markers of sleep fragmentation. Thorax. 2011;66(5): 438-45.

26 O’Donoghue FJ, Borel JC, Dauvilliers Y, Levy P, Tamisier R, Pepin JL. Effects of 1-month withdrawal of ventilatory support in hypercapnic myotonic dystrophy type 1 . Respirology. 2017;22(7):1416-22. 